OPEN ACCESS

Edited by:

Gunnar Neels Schroeder,

Queen's University Belfast, United States

Reviewed by:

Beatriz Arellano Reynoso, National Autonomous University of

Mexico, Mexico Xingmin Sun

University of South Florida, United States

*Correspondence:

Steffen Backert

Steffen.Backert@fau.de

${ }^{\dagger}$ These authors have contributed equally to this work

Specialty section:

This article was submitted to Bacteria and Host,

a section of the journal

Frontiers in Cellular and

Infection Microbiology

Received: 31 July 2020 Accepted: 27 October 2020 Published: 08 December 2020

Citation:

Sharafutdinov I, Esmaeili DS, Harrer A, Tegtmeyer N, Sticht $H$ and Backert S

(2020) Campylobacter jejuni Serine Protease HtrA Cleaves the Tight Junction Component Claudin-8. Front. Cell. Infect. Microbiol. 10:590186. doi: 10.3389/fcimb.2020.590186

\section{Campylobacter jejuni Serine Protease HtrA Cleaves the Tight Junction Component Claudin-8}

\author{
Irshad Sharafutdinov ${ }^{1 \dagger}$, Delara Soltan Esmaeili ${ }^{1 \dagger}$, Aileen Harrer ${ }^{1 \dagger}$, Nicole Tegtmeyer ${ }^{1}$, \\ Heinrich Sticht ${ }^{2}$ and Steffen Backert ${ }^{1 *}$ \\ ${ }^{1}$ Department of Biology, Division of Microbiology, University of Erlangen-Nuremberg, Erlangen, Germany, ${ }^{2}$ Division of Bioinformatics,
Institute of Biochemistry, University of Erlangen-Nuremberg, Erlangen, Germany
}

Campylobacter jejuni express the high temperature requirement protein A ( $\mathrm{Htr} A)$, a secreted serine protease, which is implicated in virulence properties of the pathogen. Previous studies have shown that $C$. jejuni HtrA can cleave the epithelial transmembrane proteins occludin and E-cadherin in the tight and adherens junctions, respectively. In the present report, we studied the interaction of HtrA with another human tight junction protein, claudin-8. Confocal immunofluorescence experiments have shown that $C$. jejuni infection of the intestinal polarized epithelial cells in vitro leads to a relocation of claudin-8. Wild-type C. jejuni induced the downregulation of claudin- 8 signals in the tight junctions and an accumulation of claudin-8 agglomerates in the cytoplasm, which were not seen during infection with isogenic $\Delta h t r A$ knockout deletion or protease-inactive S197A point mutants. Western blotting of protein samples from infected $v s$. uninfected cells revealed that an $18-\mathrm{kDa}$ carboxy-terminal fragment is cleaved-off from the 26-kDa full-length claudin-8 protein, but not during infection with the isogenic $\Delta h t r A$ mutant. These results were confirmed by in vitro cleavage assays using the purified recombinant $C$. jejuni $\mathrm{HtrA}$ and human claudin-8 proteins. Recombinant HtrA cleaved purified claudin-8 in vitro giving rise to the same $18-\mathrm{kDa}$ sized carboxy-terminal cleavage product. Mapping studies revealed that HtrA cleavage occurs in the first extracellular loop of claudin-8. Threedimensional modeling of the claudin-8 structure identified an exposed HtrA cleavage site between the amino acids alanine 58 and asparagine 59 , which is in well agreement with the mapping studies. Taken together, HtrA operates as a secreted virulence factor targeting multiple proteins both in the tight and adherens junctions. This strategy may help the bacteria to open the cell-to-cell junctions, and to transmigrate across the intestinal epithelium by a paracellular mechanism and establish an acute infection. 


\section{INTRODUCTION}

Campylobacter jejuni is a Gram-negative, microaerophilic, spiralshaped, flagellated proteobacterium that commensally colonizes the mucus layer in the lower intestinal tract of many birds and various mammals (Burnham and Hendrixson, 2018). The genus Campylobacter is evolutionarily related to the gastric pathogen Helicobacter pylori and considered to be the most common bacterial cause of human gastroenteritis in the world (Marder et al., 2017). C. jejuni represents a major zoonotic pathogen, which can be transmitted via a fecal > oral route through the consumption of contaminated poultry meats as well as other animal-derived food products (Hale et al., 2012). The rates of gastroenteric infections caused by $C$. jejuni are very high both in developed and developing countries (Kaakoush et al., 2015). Upon infection, C. jejuni appears to present lipooligosaccharides (LOS) at the bacterial cell surface, which in some patients can cross-react with human gangliosides resulting in autoimmune disorders such as the Guillian-Barré or Miller-Fisher syndromes (Ang et al., 2002; Yuki et al., 2004; Charles et al., 2017). Furthermore, in some cases this pathogen can promote colorectal cancer tumorigenesis through the action of microbial cytolethal distending toxin (CDT) (Brauner et al., 2010; He et al., 2019). Interestingly, CDT from $C$. jejuni was also extensively studied as an anti-cancer therapeutic agent for potential clinical applications (Lai et al., 2016). The pathogenic process generated by C. jejuni in the human intestine develops upon reaching the gut, where the bacteria attach to and then invade into epithelial cells, resulting in host tissue damage (Van Spreeuwel et al., 1985; Wooldridge and Ketley, 1997). Various bacterial adhesion proteins (adhesins) provide stable attachment through specific interaction with host cell receptors, which is a necessary requirement for subsequent host cell entry (Hermans et al., 2011; Backert et al., 2013). Several major adhesins were identified and have been reported to provide effective C. jejuni adhesion to a host cell, with the CadF (Campylobacter adhesin to fibronectin) protein being central in this process (Konkel et al., 1997; Schmidt et al., 2019). However, other adhesins also play important roles in cell attachment and include FlpA (fibronectin like protein A), JlpA (jejuni lipoprotein A), PEB1 (periplasmic binding protein 1), MOMP (major outer membrane protein), and some others (O Cróinín and Backert, 2012). Upon attachment, C. jejuni can enter host target cells via a signaling process involving the small Rho GTPases Racl and Cdc42 (Krause-Gruszczynska et al., 2007a; Krause-Gruszczynska et al., 2007b; Boehm et al., 2011; Krause-Gruszczynska et al., 2011; Eucker and Konkel, 2012). In addition, C. jejuni utilizes its flagellum as a type III secretion system (fT3SS) for the secretion or injection of effector proteins that interfere with host cell functions (Young et al., 1999; Christensen et al., 2009; BarreroTobon and Hendrixson, 2012). Furthermore, C. jejuni can transmigrate to the basolateral site of the intestinal epithelium by disrupting the host cellular junctions, and serine protease HtrA appears to play a driving role in this process (Boehm et al., 2018; Harrer et al., 2019).

HtrA proteins represent ATP-independent serine type proteases and are widely distributed both in prokaryotic and eukaryotic organisms (Clausen et al., 2002; Neddermann and Backert, 2019). Many bacteria can encode either one or more HtrA homologs (Li et al., 1996; Humphreys et al., 1999; Cortes et al., 2002; Purdy et al., 2002; Mo et al., 2006; Wilson et al., 2006; Ye et al., 2016). HtrA proteins due to their structure combine both protease and chaperone functions (Clausen et al., 2011). Bacterial HtrAs consist of an amino-terminal signal peptide, a trypsin-like serine protease domain and one or two PDZdomains at the carboxy-terminus that regulate interactions with itself or other proteins (Kim and Kim, 2005; SkorkoGlonek et al., 2013). Escherichia coli is considered to be the best studied model organism concerning HtrA. This species encodes as many as three HtrA homologs, namely, DegP, DegQ, and DegS (Kim and Kim, 2005; Clausen et al., 2011). Their main function is to protect the bacterium against heat and other stresses, as well as to remove misfolded proteins. For example, inactivation of the htrA gene in Streptococcus mutans has been shown to affect its resistance to low and high temperatures, low $\mathrm{pH}$ as well as oxidative and DNA damaging agents (Biswas and Biswas, 2005). HtrAs can also play a major role in the pathogenesis of other Gram-positive and Gramnegative microbes (Backert et al., 2018). For example, the human pathogen Streptococcus pyogenes with impaired HtrA function expressed reduced amounts of mature streptococcal pyrogenic exotoxin B (SpeB), as it was shown by Western blot analysis and protease assays (Cole et al., 2007). In addition, H. pylori was the first bacterium shown to secrete HtrA into the extracellular environment, which was associated with the paracellular transmigration of the pathogen through cleavage of the host adherens junction protein E-cadherin (Harrer et al., 2018).

Campylobacter jejuni encodes one HtrA homolog, whose function was analysed by biochemical assays in vitro and in the bacteria in vivo (Brondsted et al., 2005; Zarzecka et al., 2020). Cryo-electron microscopy revealed the architecture of C. jejuni HtrA defined as a dodecamer, assembled by four trimers (Zarzecka et al., 2020). However, HtrA of C. jejuni can be also secreted into the extracellular space, where it has been shown to cleave the extracellular domain of E-cadherin at various positions (Boehm et al., 2012; Hoy et al., 2012). As a result, this helps C. jejuni to transmigrate between neighbouring host cells to the basal side of polarized gut epithelium. However, prior to the reach adherence junctions, $C$. jejuni faces the tight junction barrier, consisting of several proteins including tricellulin, occludin, claudins, and junction adhesion molecules (JAMs) (Guttman and Finlay, 2009; Gunzel and Yu, 2013; Van Itallie and Anderson, 2014; Slifer and Blikslager, 2020). This multiprotein junctional complex maintains "fence" tasks providing cell polarity and "gate" function, which provides selective transport of small molecules through the apical-basal barrier (Zihni et al., 2016). In addition, tight junction transmembrane proteins bind to intracellular scaffold proteins such as zonula occludens ( $\mathrm{ZO})-1,-2$, and -3 forming tight connection with the actin cytoskeleton (Zihni et al., 2016). More recently, we have shown that $C$. jejuni can disrupt the tight junction protein occludin in an HtrA-dependent manner 
(Harrer et al., 2019). However, it is still unclear, whether other tight junction proteins such as the claudins may also be affected during C. jejuni paracellular transmigration.

Claudins represent tight JAMs responsible for the paracellular barrier function and account for at least 27 members in mammals (Tsukita et al., 2019). Based on their sequence homology, claudin family members consist of four putative transmembrane segments, a large extracellular loop (ECL1) containing a consensus sequence motif, and a second shorter extracellular loop (ECL2) also known as extracellular segments 1 and 2, respectively (Gunzel and Yu, 2013). Interestingly, C. jejuni has been shown to disrupt tight junctions during bacterial invasion of non-tumorigenic canine intestinal epithelial cells through claudin-4 cleavage (Lamb-Rosteski et al., 2008). Fluorescence microscopy revealed that infection of the epithelial monolayer with $C$. jejuni results in disruption of pericellular claudin-4, while Western blotting showed significantly less total claudin-4 (Lamb-Rosteski et al., 2008). However, the molecular background of claudin degradation during C. jejuni infection remained unclear. C. jejuni has been already shown to disrupt the major junction proteins occludin and E-cadherin during paracellular migration in an HtrAdependent manner (Boehm et al., 2012; Harrer et al., 2019), which may be associated with shedded outer-membrane vesicles (Elmi et al., 2018). The results presented here suggest that claudin-8 is a major novel cleavage target for C. jejuni HtrA, and besides occludin, the second target protein in the tight junctions, which may help the pathogen to disrupt the epithelial barrier during infection.

\section{MATERIALS AND METHODS}

\section{Campylobacter Strains and Infection Assays}

The C. jejuni wild-type (wt) strain 81-176 and its isogenic knockout mutant C. jejuni $\Delta h t r A$, the complemented mutant $\Delta h t r A / h t r A$ and protease-inactive S197A point mutation in the $h \operatorname{tr} A$ gene were used throughout this study (Boehm et al., 2012; Boehm et al., 2015). Bacterial cells were cultured using Campylobacter blood-free selective agar base including Campylobacter growth supplement provided by Oxoid (Wesel, Germany). Alternatively, the bacteria were grown on Mueller-Hinton ( $\mathrm{MH}$ ) agar supplemented with chloramphenicol $(20 \mu \mathrm{g} / \mathrm{ml})$ or kanamycin $(30 \mu \mathrm{g} / \mathrm{ml})$, respectively. Incubation was for $48 \mathrm{~h}$ at $37^{\circ} \mathrm{C}$ in jars using microaerobic conditions provided by the CampyGen ${ }^{\mathrm{TM}}$ system from Oxoid. All C. jejuni strains were harvested using sterile cotton swabs and resuspended in liquid $\mathrm{BHI}$ medium. The optical density (OD) was measured at $600 \mathrm{~nm}$ in an Eppendorf spectrophotometer to calculate the number of bacterial cells followed by host cell infection of C. jejuni using a multiplicity of infection (MOI) of 100.

\section{Cell Culture and Immunofluorescence Staining}

The human intestinal cell lines Caco-2 (ATCC HTB-37) and T84 (ATCC CCL-248) were seeded into $75 \mathrm{~cm}^{2}$ cell culture flasks and finally in 12-well plates using DMEM medium including 10\% FCS (Invitrogen) and $4 \mathrm{mM}$ glutamine (Invitrogen, Karlsruhe, Germany). The cells formed proper monolayers and were incubated for 14 days to allow proper cell polarization. After a 12-h co-incubation with C. jejuni, the infected cells were washed twice with sterile PBS buffer followed immunofluorescence staining according to a previous protocol (Krause-Gruszczynska et al., 2007a). In brief, the cells have been fixed for $10 \mathrm{~min}$ in $4 \%$ PFA (paraformaldehyde) at $20^{\circ} \mathrm{C}$. Afterwards, the cells were permeabilized for $1 \mathrm{~min}$ using $0.25 \%$ Triton-X100 and then blocked for $1 \mathrm{~h}$ in PBS buffer containing 5\% BSA. Immunostaining of the cells was performed with the following antibodies: $\alpha$-claudin- 8 (\#710222 and \#40-0700Z, Invitrogen) and $\alpha$-occludin (\#sc-133256, Santa Cruz Biotechnology). The C. jejuni bacteria were visualized by $\alpha$-Campylobacter antibody (Dako, Glostrup, Denmark). The DNA in the nucleus was stained by DAPI (4'-6-diamidino-2-phenylindole dihydrochloride) (Thermo Fisher Scientific). TRITC (tetramethylrhodamine isothiocynate)-conjugated $\alpha$-rabbit, TRITCconjugated $\alpha$-mouse, FITC (fluorescein isothiocyanate)-conjugated $\alpha$-rabbit and Alexa-633-conjugated $\alpha$-rabbit (Thermo Fisher Scientific) were utilized as secondary antibodies. All samples were investigated by confocal fluorescence microscopy using a Leica SP5 (Leica Microsystems, Wetzlar, Germany). Excitation/emission of the fluorescence from DAPI, FITC and TRITC was processed at 405/ 413-460 nm, 488/496-550 nm, and 561/571-630 nm wavelengths, respectively. The obtained data were visualized using LAS AF computer software (Leica Microsystems). All microscopic experiments were performed at the Optical Imaging Centre Erlangen (OICE, Erlangen, Germany).

\section{Quantification of the Fluorescence Intensities of Claudin-8 and Occludin}

The images of T84 cells after confocal immunofluoresence microscopy were subjected for further analysis in the Fiji platform (Schindelin et al., 2012). Cellular localization of claudin-8 and occludin in the T84 cell monolayers was analyzed by segmentation of the tight junctions area and the cytoplasm area into regions of interest (ROIs). In the defined ROIs (tight junctions or cytoplasm), we quantified the relative fluorescence units (RFUs) of claudin-8 and occludin, respectively. The mean value of RFUs for each condition (claudin-8 in tight junctions vs. claudin-8 in the cytoplasm, occludin in tight junctions vs. occludin in the cytoplasm) was calculated from 10 cells in the T84 monolayer and presented as mean \pm standard deviation. In addition, the fluorescence intensity of cells was assessed in single representative T84 cells (mock control cells or cells infected with wt $C$. jejuni). The RFUs were counted within a straight line passing through a cell including tight junctions and the cytoplasm areas, as marked, between the yellow arrows of Figure 3B.

\section{Cloning, Expression, and Purification of C. jejuni HtrA}

Recombinant C. jejuni HtrA was purified under native conditions as described previously (Zarzecka et al., 2018). 
For this purpose, C. jejuni HtrA of strain 81-176 without the signal peptide (amino acids 17-472) was amplified from genomic DNA and cloned in the expression plasmid pGEX-6P-1 (GE Healthcare Life Sciences, Munich, Germany) as a GST-fusion protein using the restriction sites BamHI and XmaI. The expression was performed in Escherichia coli BL21 and the purification protocol was described previously in detail (Löwer et al., 2008). E. coli LPS has been removed by incubating $100 \mu \mathrm{g} /$ $\mathrm{ml}$ of HtrA for $1 \mathrm{~h}$ using $10 \mu \mathrm{g} / \mathrm{ml}$ of polymyxin B (Sigma Aldrich) at $20^{\circ} \mathrm{C}$ (Brisslert et al., 2005). The final purity of HtrA was determined to be more than $95 \%$ by SDS-PAGE electrophoresis and Coomassie staining (Moese et al., 2001).

\section{In Vitro HtrA Cleavage Assays}

Cleavage assays were performed with recombinant $C$. jejuni HtrA and purified human full-length Claudin-8 coupled to GST (\# H00009073-P01, Abnova, Taipei City, Taiwan). For this purpose, $100 \mathrm{ng}$ of GST-claudin- 8 were incubated with 30 ng of purified C. jejuni HtrA in $25 \mu \mathrm{l} 50 \mathrm{mM}$ HEPES buffer $(\mathrm{pH}$ 7.4) for $16 \mathrm{~h}$ at $37^{\circ} \mathrm{C}$. The resulting cleavage products were analysed by SDS-PAGE and Western blotting using $\alpha$-claudin- 8 , $\alpha$-GST, and $\alpha$-HtrA antibodies as described below.

\section{Western Blotting Studies}

Proteins derived from infected cells and in vitro HtrA cleavage assays were loaded on $8 \%$ SDS-PAGE gels and blotted on PVDF membranes as described (Hartung et al., 2015). Afterwards, the membranes were prepared for blocking for $1 \mathrm{~h}$ using either 3\% BSA or $5 \%$ skim milk in TBST (25 mM Tris- $\mathrm{HCl} \mathrm{pH} 7.4,140$ $\mathrm{mM} \mathrm{NaCl}, 0.1 \%$ Tween-20) buffer at $20^{\circ} \mathrm{C}$. The following antibodies were used: rabbit $\alpha$-claudin-8 (\#710222, Invitrogen), mouse $\alpha$-GAPDH (Sigma Aldrich, Taufkrichen, Germany), or rabbit $\alpha$-HtrA (Brondsted et al., 2005). These antibodies were incubated overnight at $4^{\circ} \mathrm{C}$ using the manufacturer's or published protocols. Horseradish peroxidase-conjugated $\alpha$ rabbit or polyvalent $\alpha$-mouse immunoglobulin were utilized as secondary antibodies (Life Technologies, Darmstadt, Germany). The detection of bound antibodies was accomplished using the ECL Plus chemiluminescence Western Blot kit (GE Healthcare) (Hirsch et al., 2012).

\section{Bioinformatics}

The sequence logo describing the HtrA cleavage site was generated using the "frequency plot" option of WebLogo (Crooks et al., 2004). The search for HtrA cleavage sites in claudin-8 was done with ScanProsite (de Castro et al., 2006). Modeling of the claudin-8 structure was performed with HHpred (Zimmermann et al., 2018) and Modeller (Webb and Sali, 2017) using the structure of Claudin-9 (Vecchio and Stroud, 2019) as a template. RasMol (Sayle and Milnerwhite, 1995) was used for structure analysis and visualization.

\section{Statistics}

All data were evaluated via two-tailed Mann-Whitney test with GraphPad Prism 6 (Version 6.01). The obtained p-values $p<$ $\left.0.001^{* * *}\right)$ and $p<0.0001^{* * * *}$ ) were defined as statistically significant; ns, non-significant.

\section{RESULTS}

\section{Rearrangement of Claudin-8 in the Tight Junctions of Polarized Intestinal Epithelial Cell Lines by C. jejuni HtrA}

To evaluate whether C. jejuni HtrA affects the claudin- 8 distribution in the cellular tight junctions, immunofluorescence microscopy has been applied. For this purpose, confluent Caco-2 epithelial cells were grown in monolayers for 14 days to achieve proper polarization and detectable expression of claudin-8. The cells were then infected either with $C$. jejuni wt strain 81-176 or its isogenic $\Delta h t r A$ knockout mutant. As control experiments, Caco-2 cells were infected with C. jejuni 81-176 $\Delta h t r A$ complemented either with wt $h \operatorname{tr} A\left(\Delta h \operatorname{tr} A / h \operatorname{tr} A^{\mathrm{wt}}\right)$ or a protease-inactive S197A point mutant $\left(\Delta h t r A / h t r A^{\mathrm{SA}}\right)$. After $12 \mathrm{~h}$ of infection, Caco-2 cells were fixed in PFA and immunostained with antibodies against claudin-8 and C. jejuni as labelled with green and red fluorophores, respectively. Immunofluorescence microscopy revealed that non-infected Caco-2 monolayers are characterized by the uniform distribution of claudin- 8 in the tight junction areas (Figure 1A), while infection with wt $C$. jejuni or the wt complemented strain ( $\Delta h t r A / h t r A^{\text {wt }}$ ) led to mislocalization of claudin-8 out of the tight junctions to form agglomerates in the cytoplasm (Figures 1B, E, white arrows). Interestingly, when Caco-2 monolayers were infected with $C$. jejuni carrying deleted $h t r A$ or the protease-inactive $h t r A^{\text {S197A }}$ point-mutated gene, claudin-8 localization within cellular tight junctions was not or only slightly affected (Figures 1C, D).

To corroborate the above findings with claudin-8, we utilized a second intestinal epithelial cell line, T84. To this end, T84 cell monolayers were grown for 14 days and then infected with the above described $C$. jejuni strains under identical conditions. Besides claudin-8, we additionally counterstained the cells with the tight junction protein occludin, which we have shown recently to be cleaved by C. jejuni HtrA (Harrer et al., 2019). As expected, in non-infected T84 control cells or cells infected with $C$. jejuni carrying a defective htrA gene, both proteins (occludin and claudin-8) revealed similar staining patterns in the cellular tight junctions (Figures 2A, C, D). In contrast, infection with wt $C$. jejuni or the wt complemented strain $\left(\Delta h t r A / h t r A^{\mathrm{wt}}\right)$ led to the disruption of both occludin and claudin-8 in tight junctions along with their appearance in the cytoplasmic area (Figures $\mathbf{2 B}$, E, white arrows). The inlays on top of each panel show enlarged sections of tight junctions from corresponding areas marked with smaller white boxes.

\section{Quantification of Claudin-8 Signals in the Tight Junctions and Cytoplasm During C. jejuni Infection}

To further analyze the distribution of occludin and claudin-8 in the host cells, we quantified the mean fluorescence intensity of the proteins in the areas of membrane-associated tight junctions and cytoplasm within the overall cell population. In mock control cells, both occludin and claudin-8 revealed a higher fluorescence intensity within the tight junctions compared to 


\section{C. jejuni 81-176}

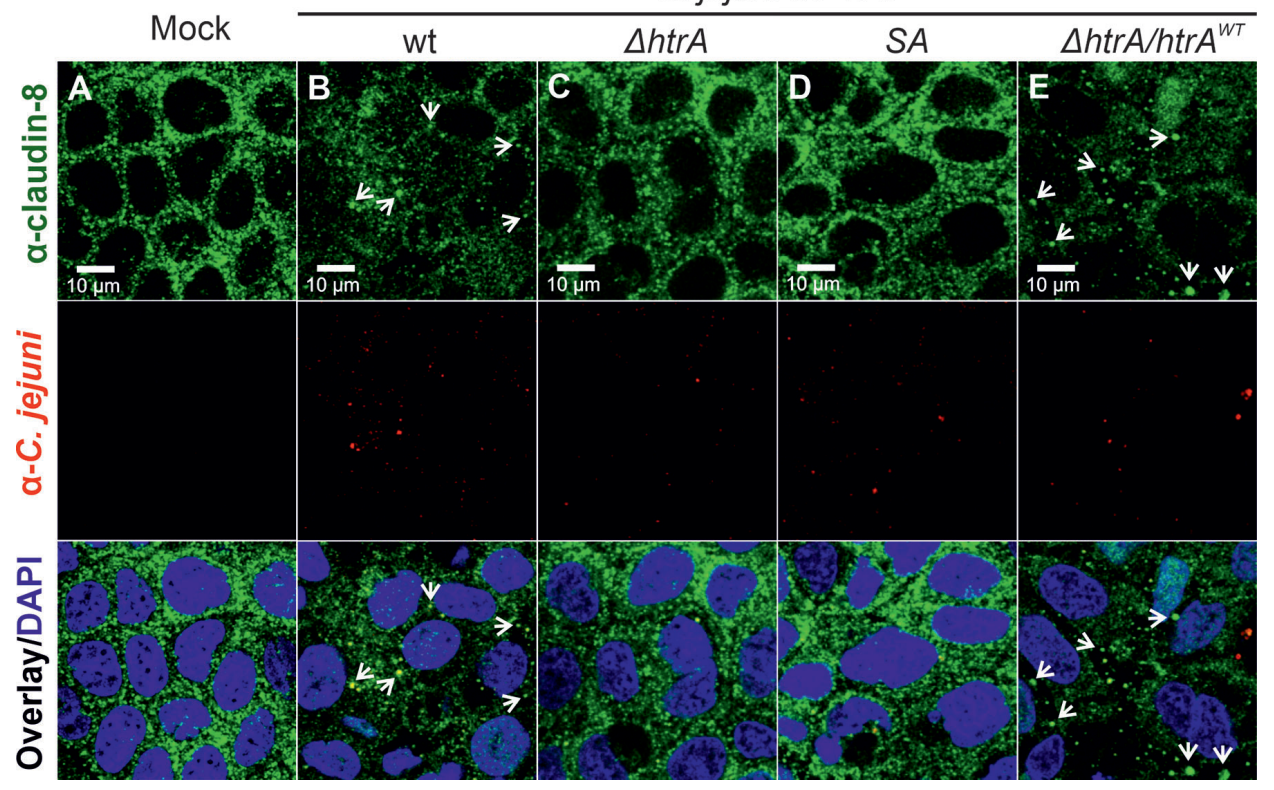

FIGURE 1 | Infection of polarized Caco-2 epithelial cell monolayers by C. jejuni 81-176 results in the disruption of claudin-8 patterns. Epithelial cells were immunostained with $\alpha$-claudin-8 (green) and $\alpha$-C. jejuni (red) without infection (A), or after infection with C. jejuni wild-type (wt) strain (B), $\Delta$ tr A knockout mutant (C), $\Delta$ trA complemented with protease inactive SA mutant (D) or wt $h$ trA (E). Infection was performed for $12 \mathrm{~h}$ at an MOI of 100 . DAPI staining (blue) was used for the nuclear DNA counterstaining. White arrows indicate claudin-8 redistribution to agglomerates.

the cytoplasmic proteins (Figure 3A). Similar patterns of occludin and claudin- 8 in the tight junctions were found in T84 cells infected with $C$. jejuni carrying an impaired $h$ trA gene. In contrast, infection of T84 cells with wt C. jejuni or the wt complemented strain led to a significant drop of fluorescence intensity of occludin and claudin-8 in the cellular tight junctions. In particular, the mean fluorescence of cytosolic occludin slightly increased when infected with wt $C$. jejuni $(p<0.0001)$ or with the wt complemented strain $(p<0.01)$, which is in agreement with our previous studies (Harrer et al., 2019). The mean fluorescence of cytosolic claudin- 8 upon infection did not change significantly within overall cell populations. However, the bright fluorescent aggregates of the cytosolic claudin-8 were only detected in T84 cells infected with wt $C$. jejuni carrying an intact $h t r A$ gene, confirming the re-distribution of the protein from the cell membrane (Figure 2, white arrows and Figure 3B). The fluorescence intensity of cells was further assessed in representative single cells between the yellow arrows as marked in Figure 3B. In non-infected T84 cells the peaks of fluorescence for occludin and claudin-8 appeared in the cell periphery, suggesting their prevailing membrane localization (Figure 3C). After infection of T84 cells with wt $C$. jejuni, the fluorescence intensity of occludin and claudin- 8 at the cell periphery was significantly reduced. Moreover, in infected T84 cells the strong fluorescence signals of claudin-8 (comparable to the fluorescence of the protein in the membrane of non-infected cells) were also detectable in the cytoplasm (Figure 2, white arrows, and Figure 3C). Based on these immunofluorescence experiments, we can conclude that HtrA is involved in the disturbance of claudin- 8 and its translocation from tight junctions into the cytoplasm during infection with C. jejuni.

\section{HtrA Induces Claudin-8 Cleavage During C. jejuni Infection of Polarized Intestinal Epithelial Cells}

Since infection by $C$. jejuni expressing intact HtrA leads to disorganisation of claudin- 8 in Caco- 2 cells, we came into assumption that HtrA might have a specific proteolytic activity against claudin-8. To test whether C. jejuni HtrA is inherently involved in claudin- 8 proteolytic cleavage, immunoblotting assays were used. Polarized Caco- 2 monolayers were infected with either wt $C$. jejuni, expressing intact HtrA or $\Delta h t r A$ deletion mutant. After 12-h infection, immunoblotting was applied by using $\alpha$-claudin- $8, \alpha$-HtrA and $\alpha$-GAPDH antibodies (Figure 4A). When infected with wt $C$. jejuni we observed full-length claudin- 8 at about $26 \mathrm{kDa}$, and an additional band of lower intensity that appeared at approximately $18 \mathrm{kDa}$. In contrast, Caco-2 cells that were exposed to htrA-deficient C. jejuni, an 18$\mathrm{kDa}$ band was not detected, assuming the absence of cleavage. The immunogenicity of $\alpha$-claudin- 8 antibody is directed against amino acids 206-225 at the carboxy-terminus of the protein, which corresponds to the QKSYHTGKKSPSVYSRSQYV sequence. Since the antibody recognized an $18-\mathrm{kDa}$ claudin- 8 fragment, we proposed that this fragment corresponds to the carboxy-terminus and cleavage of claudin- 8 by C. jejuni HtrA takes place at the amino-terminus of the protein, presumably located in the first extracellular loop (Figures 4B, C). We were not able to detect the remaining very small amino-terminal 


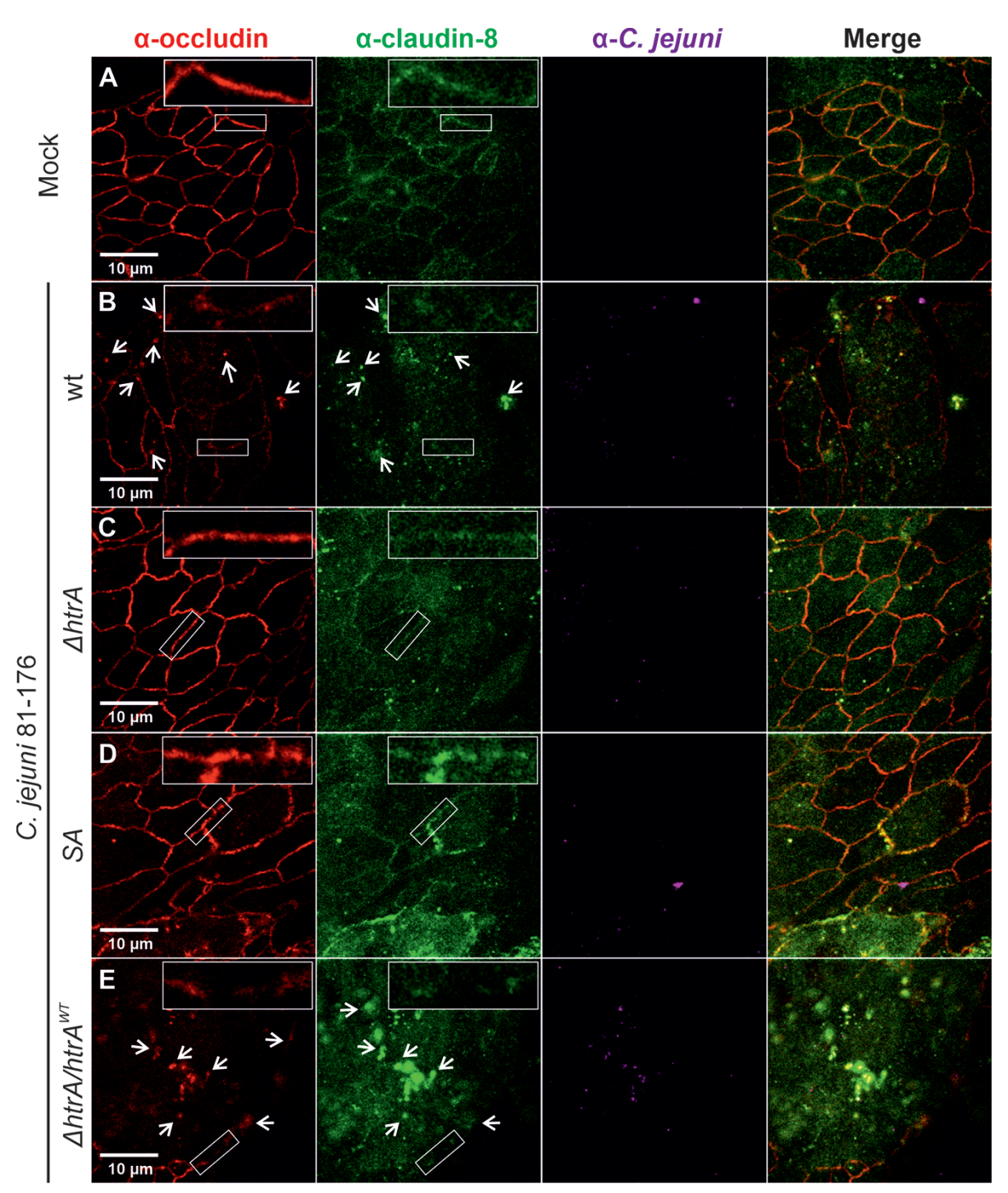

FIGURE 2 | Infection of polarized T84 epithelial cell monolayers by C. jejuni 81-176 leads to disruption of claudin-8 and occludin in the tight junctions. Epithelial cells were immunostained with $\alpha$-occludin (red), $\alpha$-claudin-8 (green) and $\alpha$-C. jejuni (magenta) without infection (A), or after infection with C. jejuni wild-type (wt) strain (B), $\Delta h t r A$ knockout mutant (C), protease inactive SA mutant (D) or $\Delta h t r A$ complemented with wt $h t r A$ (E). White arrows indicate occludin and claudin-8 redistribution to protein agglomerates. White boxes contain enlarged parts of tight junctions from corresponding smaller white boxes.

cleaved peptide of claudin- 8 due to lack of antibodies against this part of the amino-terminal tail.

\section{C. jejuni HtrA Cleaves Claudin-8 by an In Vitro Cleavage Assay}

To confirm whether the carboxy-terminal $18-\mathrm{kDa}$ fragment of claudin- 8 cleavage is the result of direct HtrA proteolytic activity, and not by any other bacterial or cellular protease, an in vitro cleavage assay using the recombinant proteins was conducted. For this purpose, we utilized recombinant amino-terminally GST-tagged claudin-8 (rGST-Claudin-8, about $51 \mathrm{kDa}$ ), which was incubated with purified C. jejuni $\mathrm{HtrA}$ for $12 \mathrm{~h}$ at $37^{\circ} \mathrm{C}$. The in vitro cleavage reactions were subjected to immunoblotting using $\alpha$-claudin-8, $\alpha$-GST and $\alpha$-HtrA antibodies.
The immunostaining with $\alpha$-claudin- 8 revealed the appearance of the same sized carboxy-terminal $18-\mathrm{kDa}$ fragment of claudin8 through cleavage by HtrA (Figure 5A). GST is a protein of 25 $\mathrm{kDa}$. The remaining $\mathrm{N}$-terminal fragment was detected after staining with $\alpha$-GST at $33 \mathrm{kDa}$, which corresponds to the GST protein fused to the cleaved $8-\mathrm{kDa}$ amino-terminus of claudin- 8 (Figures 5A, B).

\section{Mapping of the C. jejuni HtrA Cleavage Site for Claudin-8 Proteolysis}

The sequence preferences for $C$. jejuni HtrA cleavage were identified recently based on the cleavage sites detected in the $\beta$-casein and lysozyme substrates by mass spectrometry (Zarzecka et al., 2020). This analysis revealed that the cleavage 


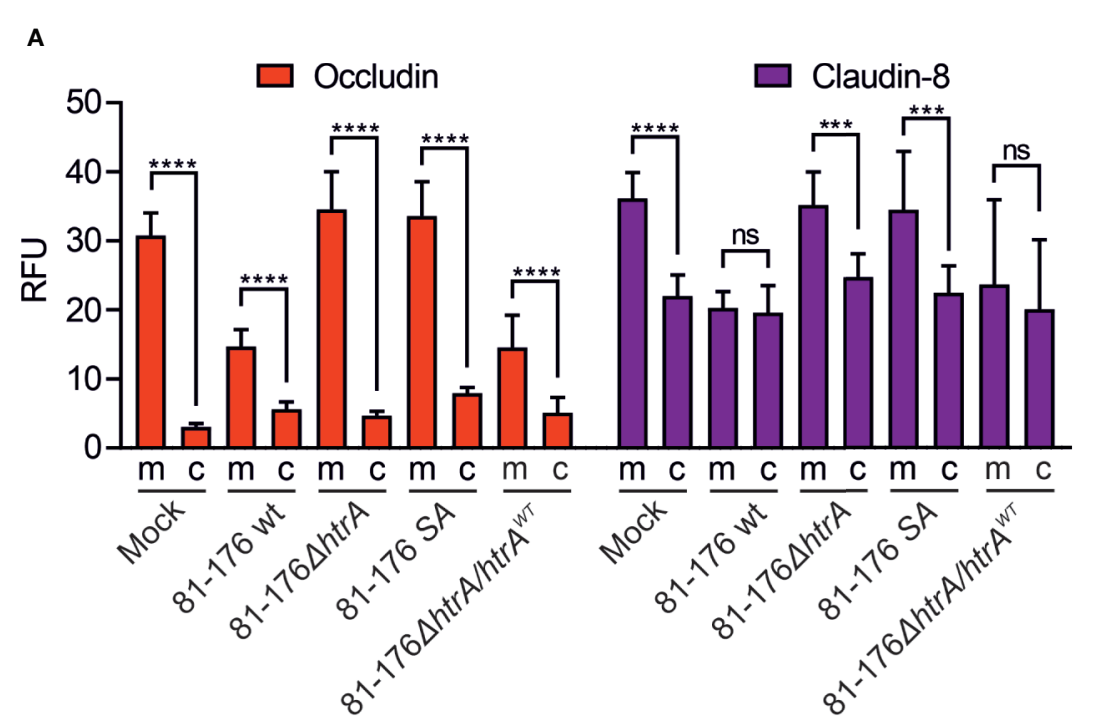

B

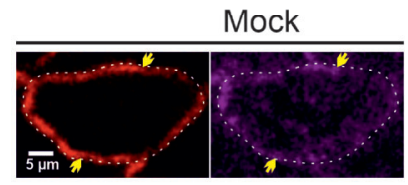

$\alpha-$ occludin $\alpha$-claudin-8

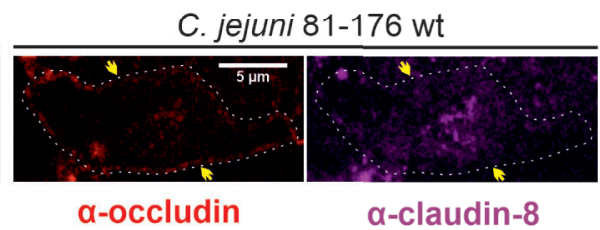

C

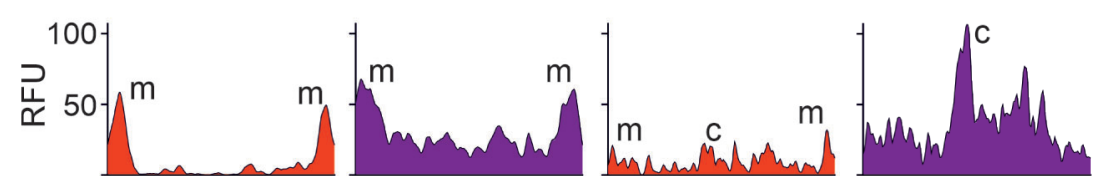

FIGURE 3 | Localization of occludin and claudin-8 proteins in tight junctions and cytoplasm of T84 cells. The mean florescence intensity of the proteins was assessed separately in the membrane (m)-associated tight junctions and cytoplasm (c), and was calculated from 10 T84 cells per sample (A). Single cell analysis of representative T84 cells without or with infection by wt $C$. jejuni. Infection of T84 cells leads to the drop of fluorescence intensity of claudin-8 in tight junctions along with its appearance in the cytoplasm (B). Corresponding fluorescence intensity plots for occludin and claudin- 8 within single cells between two yellow arrows, as marked in panel (B). When infected with wt C. jejuni, a strong fluorescence intensity can be found in the cell cytoplasm (C). RFU, relative fluorescence units of membrane and cytoplasmic localization. ${ }^{\star \star \star} \mathrm{p}<0.001,{ }^{\star \star \star \star} \mathrm{p}<0.0001$, ns, non-significant.

site exhibits a rather large sequence heterogeneity and that the highest conservation is observed for the P1 and P1' sites. Based on the three predominant residues observed at the P1 and P1' site, we defined the pattern [VAL]-[SKN] to search for HtrA cleavage sites in the extracellular domain 1 (ECD1) of claudin-8. A frequency plot of the HtrA cleavage sites was established (Figure 6A). The height of each character is proportional to the frequency of the amino acid residue at the individual position of the cleaved peptide. This analysis revealed that there are three instances of this pattern in ECD1, namely, V32-S33, A58-N59, and L73-S74. The location of these sites in the claudin-8 structure is shown in Figures 6B, C. The V32-S33 site is buried in a $\beta$-sheet and therefore only hardly accessible to HtrA cleavage. The L73-S74 site is located in the immediate vicinity to a transmembrane helix; therefore, cleavage is sterically hindered by the presence of the membrane. In contrast, A58-N59 is located in an exposed turn connecting two $\beta$-strands and therefore is accessible. Thus, the A58-N59 position represents the most likely site for C. jejuni HtrA cleavage in claudin-8.

\section{DISCUSSION}

The tight junctions in the intestine play a major role both in epithelial cell monolayer integrity and in selective transport of molecules across neighboring epithelial cells. The key proteins building the tight junction net include claudin family members, occludin and tricellulin that localize at the upper tricellular contacts facing the lumen. During infection, some microbial pathogens can target the tight junction complex leading to protein dysregulation, which results in the disruption of intestinal barrier homeostasis in order to support microbial survival, spread and sometimes persistence (Vogelmann et al., 2004). For example, the human pathogen Vibrio cholerae secretes 


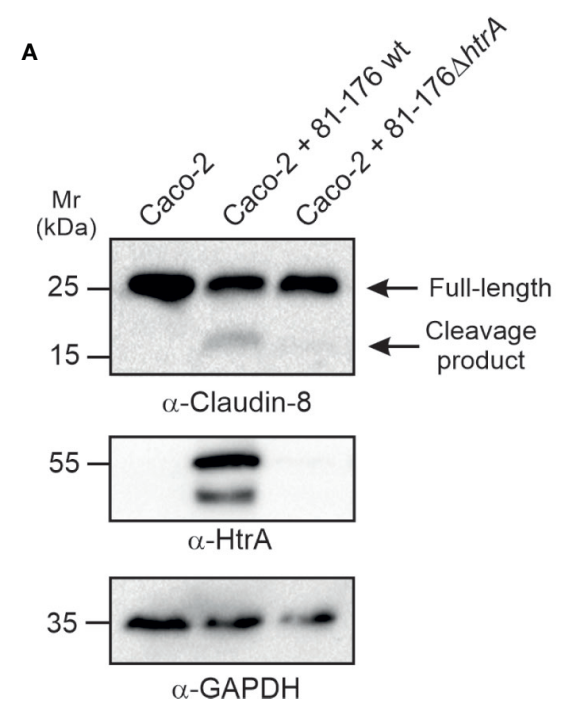

B
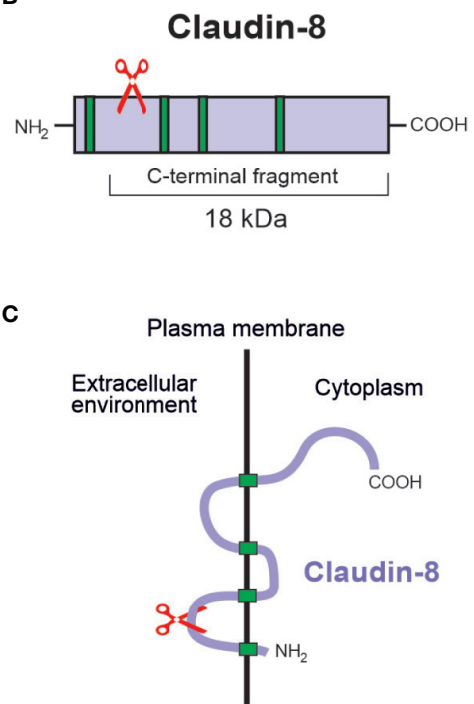

FIGURE 4 | HtrA cleaves claudin-8 during C. jejuni infection in vivo. (A) Immunoblotting of protein extracts from polarized Caco-2 cell monolayers infected with C. jejuni wild-type (wt) or $\Delta$ htrA mutant. The blots were stained with polyclonal $\alpha$-claudin-8 antibodies recognizing the carboxy-terminus of the protein. The $\alpha$-HtrA and $\alpha$-GAPDH blots served as controls. Besides the full-length protein $(\sim 26 \mathrm{kDa})$, a cleaved carboxy-terminal fragment $(\sim 18 \mathrm{kDa})$ was visualized with $\alpha$ - claudin-8 antibodies upon infection with C. jejuni wt. (B) Proposed cleavage site position in the amino-terminus of claudin-8 for HtrA protease according to the size of protein cleavage products determined by SDS-PAGE marker proteins. (C) A model for claudin-8 cleavage in the first extracellular loop (ECL1) by HtrA protease.

a metalloprotease, haemagglutinin/protease (HA/P), which degrades the occludin extracellular domain and subsequently affects the host cell actin cytoskeleton due to impaired interactions with the scaffold protein ZO-1 (Schubert-Unkmeir et al., 2010). Neisseria meningitidis was shown to activate matrix metalloproteinase 8 in human brain microvascular endothelial cells, resulting in cleavage of occludin. This resulted in disappearance of occludin from the cell periphery and cleavage to a lower-sized 50-kDa protein (Schubert-Unkmeir et al., 2010). Finally, multiple Gram-negative bacteria including C. jejuni, H. pylori, Escherichia coli, and Shigella flexneri secrete the HtrA protease towards adherence junctions, where it cleaves the adherens junction receptor protein E-cadherin (Schmidt et al., 2016). Recently, C. jejuni HtrA was shown to cleave Ecadherin and occludin upon infection of intestinal polarized Caco-2 cells (Harrer et al., 2019). In our previous analysis, we have identified the cleavage sites of $H$. pylori HtrA in the Ecadherin protein with a consensus cleavage sequence occurring at the [VITA]-[VITA]-x-x-D-[DN] motif (Schmidt et al., 2016). We have then identified a simplified pattern [VITA]-[VITA]-x $(2,4)-[\mathrm{DN}]$ of an HtrA cleavage site in occludin, which occurred in the second extracellular loop and was characterized by lack of secondary structure (Harrer et al., 2019). The present results shown here demonstrate that HtrA from C. jejuni can cleave another major tight junction protein, claudin- 8 , as this has been shown both in vitro with purified proteins and upon infection of cultured polarized Caco-2 and T84 cells in vivo.

Claudins represent highly conserved 20 - to $27-\mathrm{kDa}$ proteins that are differentially expressed along the various epithelial compartments of the gastrointestinal tract (Kim et al., 2019).
Claudins are composed of four transmembrane regions including a short intracellular amino-terminal sequence ( $\sim 1-7$ residues), a large first extracellular loop ( $\sim 52$ residues), a shorter second extracellular loop (16-33 residues), and a cytoplasmic carboxyterminal domain that varies considerably in length between different isoforms (21-63 residues) (Kim et al., 2019). The function of these proteins is mainly determined by their extracellular loops ECL1 and ECL2 (Krause et al., 2008). When the larger ECL1 is supposed to provide paracellular tightness and the selective ion permeability, the smaller ECL2 might contribute in narrowing of the paracellular cleft and hold neighboring cell membranes (Wen et al., 2004; Piontek et al., 2008). The decreased barrier function due to disruption of tight junctions leads to alterations in levels of pro-inflammatory signaling that apparently results in variety of pathologies (Harhaj and Antonetti, 2004; Turner, 2006). Thus, dysregulation of claudins in the gastrointestinal tract can lead to various illnesses such as inflammatory bowel disease, celiac disease and gastroesophageal reflux disease (Zeissig et al., 2007; Szakal et al., 2010; Monkemuller et al., 2012). Claudin-8, in particular, has been shown to be expressed in the small and large intestines, liver and gallbladder and to be involved in the tight junction barrier function (Jeansonne et al., 2003; Kim et al., 2019). Downregulation and redistribution of claudin- 8 along with claudin-5 lead to alterations in tight junction's structure and pronounced barrier dysfunction both in mild and moderately active Crohn's disease (Zeissig et al., 2007).

Since claudin-8 plays an important role in barrier function of intestinal epithelial cell monolayers, we aimed to elucidate if this tight junction protein could be a target for C. jejuni HtrA. 
A
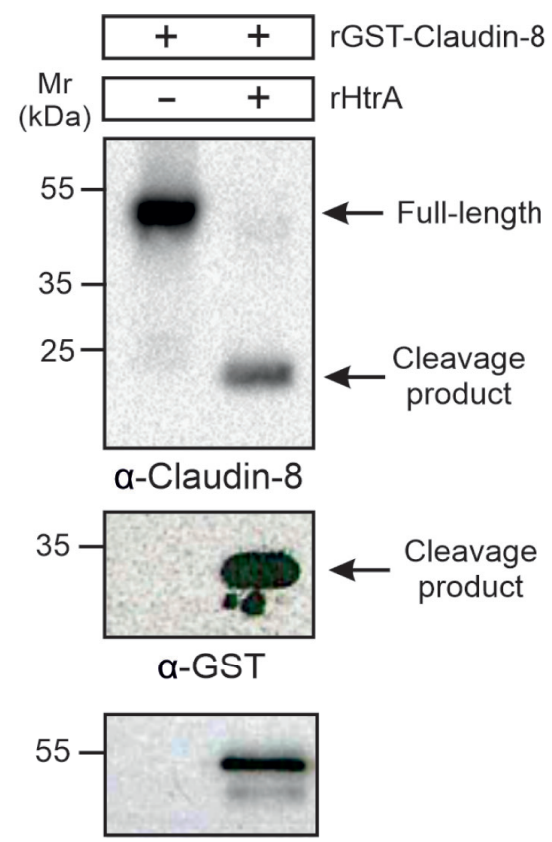

$\alpha-\mathrm{H} \operatorname{trA}$

B $51 \mathrm{kDa}$

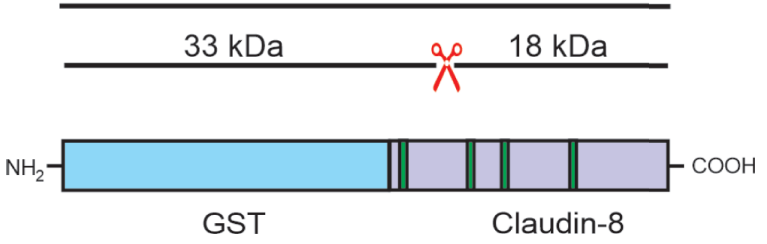

FIGURE 5 | HtrA cleaves claudin-8 in a cleavage assay in vitro.

(A) Recombinant GST-tagged human claudin-8 was incubated with either purified $\mathrm{rHtrA}$ in vitro. Immunoblotting against $\alpha$-claudin- 8 showed cleavage of the full-length GST-tagged claudin-8 protein, when incubated with recombinant HtrA resulted in the appearance of an $18-\mathrm{kDa}$ claudin-8 fragment. In addition, a cleaved 33-kDa fragment was visualized in the blot with $\alpha$-GST antibodies. (B) Mapping of the GST-claudin-8 cleavage fragments. The full-length GST-tagged claudin-8 protein $(51 \mathrm{kDa})$ is cleaved into a carboxy-terminal $18-\mathrm{kDa}$ fragment of claudin-8 and a $33 \mathrm{kDa}$ aminoterminal fragment containing the GST-tag and the remaining 8-kDa aminoterminal fragment of claudin-8.

We have previously shown that upon infection of Caco-2 wt cells, C. jejuni exploits the secreted serine protease HtrA to cleave the adherens junction protein E-cadherin (Boehm et al., 2012). Then, we have demonstrated that both the apical tight junction proteins occludin (Harrer et al., 2019) and claudin-8 (this work) are also disrupted by HtrA during C. jejuni infection facilitating pathogen entry into the intercellular space between neighboring cells of the gut epithelium. This approach may help the bacteria to transmigrate across the intestinal epithelium by a paracellular mechanism and reach basal surfaces and the fibronectin-integrin complex that connect epithelial cells with underlying tissue (Backert et al., 2013; Backert et al., 2018). In particular, C. jejuni uses the fibronectin and integrin receptors to enter
A
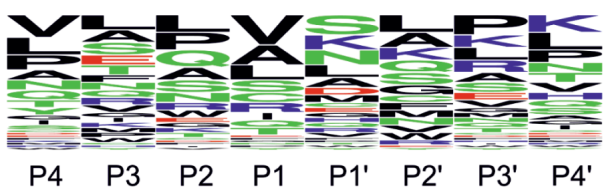

B

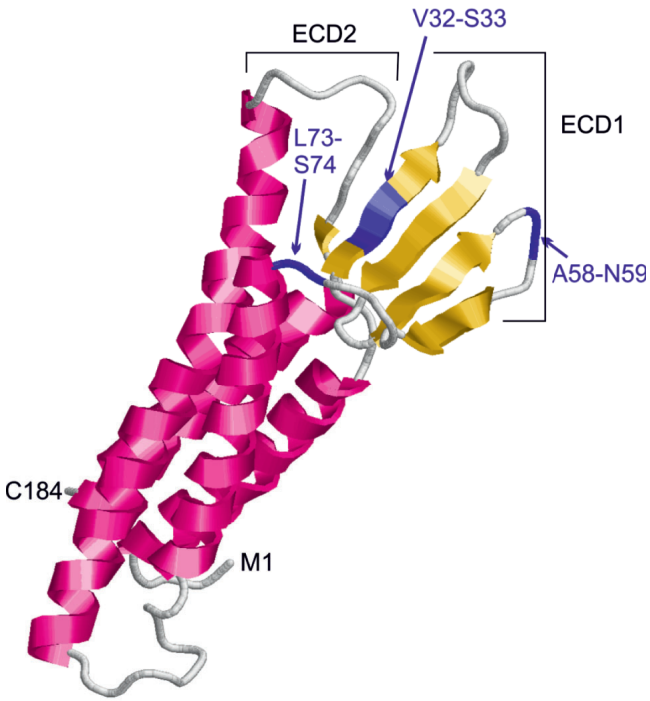

C

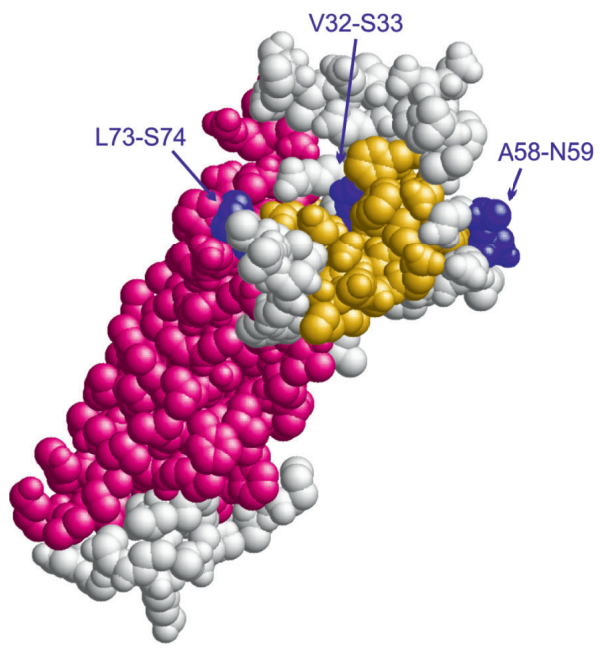

FIGURE 6 | Identification of candidate HtrA cleavage sites in human claudin8. (A) Sequence logo derived from the HtrA cleavage sites in $\beta$-casein and lysozyme. The height of the letters is proportional to the relative frequency of the amino acid at the respective sequence position (P4 to P4') denote the individual positions of the HtrA cleavage site. (B) Model of the claudin-8 structure indicating the position of candidate cleavage sites (blue) in the extracellular domain 1 that confer the pattern [VAL]-[SKN]. (C) The spacefilled-presentation of claudin-8 shows that only the A58-N59 site is fully accessible for recognition by a protease.

host cells in a CadF/FlpA-dependent manner (Boehm et al., 2011; Krause-Gruszczynska et al., 2011; Eucker and Konkel, 2012). While some major junctional proteins such as claudin8 , occludin and E-cadherin are targeted by HtrA, $h$ trA-deficient bacteria do not and are strongly diminished in transmigration, 
adhesion and invasion of polarized Caco-2 cells (Harrer et al., 2019).

While tight junctions are essential in regulating the permeability across the epithelia, tight junctions can also mediate signaling pathways in response to other factors, for instance, through phosphorylation (Nunbhakdi-Craig et al., 2002; Fujibe et al., 2004). This can directly regulate the permeability of the cell monolayer, by promoting the barrier function or increasing $\mathrm{Mg}^{2+}$ transport (Ishizaki et al., 2003; Ikari et al., 2008). For example, a mutant protein kinase WNK4 present in patients with the pseudohypoaldosteronism type II disorder was found to phosphorylate claudins 1-4 resulting in elevated paracellular permeability (Yamauchi et al., 2004). In general, phosphorylation of claudins appeared as a vital process required for the maintenance of cell homeostasis but this also makes it an attractive target for the pathogens. Though we did not determine the claudin- 8 phosphorylation status in the present report, due to lack of corresponding antibodies, $C$. jejuni HtrA could either potentially affect phosphorylationmediated downstream signaling via claudin- 8 or directly cleave target proteins. This idea should be studied in more detail in future experiments. Finally, tight junction proteins such as the claudins can be targeted not only by $C$. jejuni, but also other microbial pathogens. For instance, $H$. pylori HtrA can also cleave claudin- 8 resulting in the same $18-\mathrm{kDa}$ carboxy-terminal fragment (Tegtmeyer et al., 2017). This suggests that H. pylori and $C$. jejuni HtrAs most likely cleave the same sequence between the A58-N59 position in claudin-8. In addition, Clostridium perfringens has been shown to destroy the epithelial cell layer through the interaction of an enterotoxin with the claudin- 4 protein by using it as a host cell receptor (Eichner et al., 2017). In a similar way, C. perfringens enterotoxin has been found to interact with other claudin members including claudin-5, $-6,-8$ and -14 , confirming that they share a similar structural topology (Lal-Nag et al., 2012; Shrestha and McClane, 2013; Liao et al., 2016). Thus, the claudins in the tight junctions represent preferred targets by multiple microbial pathogens.

Taken together, we found that $C$. jejuni, in addition to occludin and E-cadherin, is capable to cleave claudin-8, which results in the disruption of major junction proteins in an HtrAdependent manner. Thereby, this microbial pathogen can reach the basal side of polarized epithelial cells by transmigration through the tight and adherens junctions disrupted by secreted HtrA. However, cleavage of occludin and claudin- 8 by $C$. jejuni HtrA might be just one option for the paracellular

\section{REFERENCES}

Ang, C. W., Laman, J. D., Willison, H. J., Wagner, E. R., Endtz, H. P., De Klerk, M. A., et al. (2002). Structure of Campylobacter jejuni lipopolysaccharides determines antiganglioside specificity and clinical features of Guillain-Barre, and Miller Fisher patients. Infect. Immun. 70, 1202-1208. doi: 10.1128/ iai.70.3.1202-1208.2002

Backert, S., Boehm, M., Wessler, S., and Tegtmeyer, N. (2013). Transmigration route of Campylobacter jejuni across polarized intestinal epithelial cells: paracellular, transcellular or both? Cell. Commun. Signal. 11, 72. doi: 10.1186/ $1478-811 x-11-72$ transmigration, while another intriguing mechanism could be the control of potential phosphorylation of claudins triggered by bacterium. C. jejuni is widely known to hijack host molecular signaling for its own benefit, for instance, by phosphorylation of host cell receptors such as EGFR, PDGFR and other signaling proteins (Tegtmeyer et al., 2020), and further investigation of this strategy can provide new insights in the pathogenesis of these important bacteria.

\section{DATA AVAILABILITY STATEMENT}

The raw data supporting the conclusions of this article will be made available by the authors, without undue reservation.

\section{AUTHOR CONTRIBUTIONS}

IS, DS, and AH performed the infection studies. IS performed the immunofluorescence experiments. DS, AH, and NT did the in vitro cleavage experiments. HS performed the bioinformatics analysis and cleavage site identification. IS analyzed the data. SB conceptualized the study, analyzed the data, and wrote the paper together with IS. All authors contributed to the article and approved the submitted version.

\section{FUNDING}

This work is supported by German Federal Ministries of Education and Research (BMBF) in frame of the zoonoses research consortium PAC-Campylobacter to SB (IP9/ $01 \mathrm{KI} 1725 \mathrm{E}$ ) and by the German Science Foundation (DFG) to NT (TE776/3-1). We thank the FAU University Erlangen for their support to publish Open Access papers. We thank the FAU University Erlangen for their support to publish Open Access papers.

\section{ACKNOWLEDGMENTS}

We thank Wilhelm Brill and Nina Rottmann for excellent technical assistance.

Backert, S., Bernegger, S., Skorko-Glonek, J., and Wessler, S. (2018). Extracellular HtrA serine proteases: An emerging new strategy in bacterial pathogenesis. Cell. Microbiol. 20, e12845. doi: 10.1111/cmi.12845

Barrero-Tobon, A. M., and Hendrixson, D. R. (2012). Identification and analysis of flagellar coexpressed determinants (Feds) of Campylobacter jejuni involved in colonization. Mol. Microbiol. 84, 352-369. doi: 10.1111/j.1365-2958.2012.08027.x

Biswas, S., and Biswas, I. (2005). Role of HtrA in surface protein expression and biofilm formation by Streptococcus mutans. Infect. Imum. 73, 6923-6934. doi: 10.1128/iai.73.10.6923-6934.2005

Boehm, M., Krause-Gruszczynska, M., Rohde, M., Tegtmeyer, N., Takahashi, S., Oyarzabal, O. A., et al. (2011). Major host factors involved in epithelial cell 
invasion of Campylobacter jejuni: role of fibronectin, integrin betal, FAK, Tiam-1, and DOCK180 in activating Rho GTPase Rac1. Front. Cell Infect. Microbiol. 1, 17. doi: 10.3389/fcimb.2011.00017

Boehm, M., Hoy, B., Rohde, M., Tegtmeyer, N., Baek, K. T., Oyarzabal, O. A., et al. (2012). Rapid paracellular transmigration of Campylobacter jejuni across polarized epithelial cells without affecting TER: role of proteolytic-active HtrA cleaving E-cadherin but not fibronectin. Gut Pathog. 4, 3. doi: 10.1186/ 1757-4749-4-3

Boehm, M., Lind, J., Backert, S., and Tegtmeyer, N. (2015). Campylobacter jejuni serine protease HtrA plays an important role in heat tolerance, oxygen resistance, host cell adhesion, invasion, and transmigration. Eur. J. Microbiol. Immunol. (Bp) 5, 68-80. doi: 10.1556/eujmi-d-15-00003

Boehm, M., Simson, D., Escher, U., Schmidt, A. M., Bereswill, S., Tegtmeyer, N., et al. (2018). Function of Serine Protease HtrA in the Lifecycle of the Foodborne Pathogen Campylobacter jejuni. Eur. J. Microbiol. Immunol. (Bp) 8, 70-77. doi: 10.1556/1886.2018.00011

Brauner, A., Brandt, L., Frisan, T., Thelestam, M., and Ekbom, A. (2010). Is there a risk of cancer development after Campylobacter infection? Scand. J. Gastroenterol. 45, 893-897. doi: 10.3109/00365521003734133

Brisslert, M., Enarsson, K., Lundin, S., Karlsson, A., Kusters, J. G., Svennerholm, A. M., et al. (2005). Helicobacter pylori induce neutrophil transendothelial migration: role of the bacterial HP-NAP. FEMS Microbiol. Lett. 249, 95-103. doi: 10.1016/j.femsle.2005.06.008

Brondsted, L., Andersen, M. T., Parker, M., Jorgensen, K., and Ingmer, H. (2005). The HtrA protease of Campylobacter jejuni is required for heat and oxygen tolerance and for optimal interaction with human epithelial cells. Appl. Environ. Microbiol. 71, 3205-3212. doi: 10.1128/aem.71.6.3205-3212.2005

Burnham, P. M., and Hendrixson, D. R. (2018). Campylobacter jejuni: collective components promoting a successful enteric lifestyle. Nat. Rev. Microbiol. 16, 551-565. doi: 10.1038/s41579-018-0037-9

Charles, J. L., Bell, J. A., Gadsden, B. J., Malik, A., Cooke, H., Van de Grift, L. K., et al. (2017). Guillain Barre Syndrome is induced in Non-Obese Diabetic (NOD) mice following Campylobacter jejuni infection and is exacerbated by antibiotics. J. Autoimmun. 77, 11-38. doi: 10.1016/j.jaut.2016.09.003

Christensen, J. E., Pacheco, S. A., and Konkel, M. E. (2009). Identification of a Campylobacter jejuni-secreted protein required for maximal invasion of host cells. Mol. Microbiol. 73, 650-662. doi: 10.1111/j.1365-2958.2009.06797.x

Clausen, T., Southan, C., and Ehrmann, M. (2002). The HtrA family of proteases: Implications for protein composition and cell fate. Mol. Cell. 10, 443-455. doi: 10.1016/s1097-2765(02)00658-5

Clausen, T., Kaiser, M., Huber, R., and Ehrmann, M. (2011). HTRA proteases: regulated proteolysis in protein quality control. Nat. Rev. Mol. Cell. Biol. 12, 152-162. doi: 10.1038/nrm3065

Cole, J. N., Aquilina, J. A., Hains, P. G., Henningham, A., Sriprakash, K. S., Caparon, M. G., et al. (2007). Role of group A Streptococcus HtrA in the maturation of SpeB protease. Proteomics 7, 4488-4498. doi: 10.1002/ pmic. 200700626

Cortes, G., de Astorza, B., Benedi, V. J., and Alberti, S. (2002). Role of the htrA gene in Klebsiella pneumoniae virulence. Infect. Immun. 70, 4772-4776. doi: 10.1128/IAI.70.9.4772-4776.2002

Cróinín, O., and Backert, S. (2012). Host epithelial cell invasion by Campylobacter jejuni: trigger or zipper mechanism? Front. Cell. Infect. Microbiol. 2, 25. doi: 10.3389/fcimb.2012.00025

Crooks, G. E., Hon, G., Chandonia, J. M., and Brenner, S. E. (2004). WebLogo: A sequence logo generator. Genome Res. 14, 1188-1190. doi: 10.1101/ gr.849004

de Castro, E., Sigrist, C. J. A., Gattiker, A., Bulliard, V., Langendijk-Genevaux, P. S., Gasteiger, E., et al. (2006). ScanProsite: detection of PROSITE signature matches and ProRule-associated functional and structural residues in proteins. Nucleic Acids Res. 34, W362-W365. doi: 10.1093/nar/gkl124

Eichner, M., Augustin, C., Fromm, A., Piontek, A., Walther, W., Bucker, R., et al. (2017). In Colon Epithelia, Clostridium perfringens Enterotoxin Causes Focal Leaks by Targeting Claudins Which are Apically Accessible Due to Tight Junction Derangement. J. Infect. Dis. 217, 147-157. doi: 10.1093/infdis/jix485

Elmi, A., Dorey, A., Watson, E., Jagatia, H., Inglis, N. F., Gundogdu, O., et al. (2018). The bile salt sodium taurocholate induces Campylobacter jejuni outer membrane vesicle production and increases OMV-associated proteolytic activity. Cell Microbiol. 20 (3), 12814. doi: 10.1111/cmi.12814
Eucker, T. P., and Konkel, M. E. (2012). The cooperative action of bacterial fibronectin-binding proteins and secreted proteins promote maximal Campylobacter jejuni invasion of host cells by stimulating membrane ruffling. Cell. Microbiol. 14, 226-238. doi: 10.1111/j.1462-5822.2011.01714.x

Fujibe, M., Chiba, H., Kojima, T., Soma, T., Wada, T., Yamashita, T., et al. (2004). $\operatorname{Thr}(203)$ of claudin-1, a putative phosphorylation site for MAP kinase, is required to promote the barrier function of tight junctions. Exp. Cell. Res. 295, 36-47. doi: 10.1016/j.yexcr.2003.12.014

Gunzel, D., and Yu, A. S. (2013). Claudins and the modulation of tight junction permeability. Physiol. Rev. 93, 525-569. doi: 10.1152/physrev.00019.2012

Guttman, J. A., and Finlay, B. B. (2009). Tight junctions as targets of infectious agents. Biochim. Biophys. Acta 1788, 832-841. doi: 10.1016/j.bbamem. 2008.10.028

Hale, C. R., Scallan, E., Cronquist, A. B., Dunn, J., Smith, K., Robinson, T., et al. (2012). Estimates of Enteric Illness Attributable to Contact With Animals and Their Environments in the United States. Clin. Infect. Dis. 54, S472-S479. doi: $10.1093 / \mathrm{cid} / \mathrm{cis} 051$

Harhaj, N. S., and Antonetti, D. A. (2004). Regulation of tight junctions and loss of barrier function in pathophysiology. Int. J. Biochem. Cell Biol. 36, 1206-1237. doi: 10.1016/j.biocel.2003.08.007

Harrer, A., Tegtmeyer, N., Boehm, M., and Backert, S. (2018). Overexpression of serine protease HtrA in Helicobacter pylori enhances disruption of adherens junctions, paracellular transmigration of the bacteria and type IV secretion of CagA. Helicobacter 9, 40. doi: 10.1186/s13099-017-0189-6

Harrer, A., Bucker, R., Boehm, M., Zarzecka, U., Tegtmeyer, N., Sticht, H., et al. (2019). Campylobacter jejuni enters gut epithelial cells and impairs intestinal barrier function through cleavage of occludin by serine protease HtrA. Gut Pathog. 11, 4. doi: 10.1186/s13099-019-0283-Z

Hartung, M. L., Gruber, D. C., Koch, K. N., Gruter, L., Rehrauer, H., Tegtmeyer, N., et al. (2015). H. pylori-Induced DNA Strand Breaks Are Introduced by Nucleotide Excision Repair Endonucleases and Promote NF-kappaB Target Gene Expression. Cell Rep. 13, 70-79. doi: 10.1016/j.celrep.2015.08.074

He, Z., Gharaibeh, R. Z., Newsome, R. C., Pope, J. L., Dougherty, M. W., Tomkovich, S., et al. (2019). Campylobacter jejuni promotes colorectal tumorigenesis through the action of cytolethal distending toxin. Gut 68, 289-300. doi: 10.1136/gutjnl-2018-317200

Hermans, D., Van Deun, K., Martel, A., Van Immerseel, F., Messens, W., Heyndrickx, M., et al. (2011). Colonization factors of Campylobacter jejuni in the chicken gut. Vet. Res. 42, 82. doi: 10.1186/1297-9716-42-82

Hirsch, C., Tegtmeyer, N., Rohde, M., Rowland, M., Oyarzabal, O. A., and Backert, S. (2012). Live Helicobacter pylori in the root canal of endodontic-infected deciduous teeth. J. Gastroenterol. 47, 936-940. doi: 10.1007/s00535-012-0618-8

Hoy, B., Geppert, T., Boehm, M., Reisen, F., Plattner, P., Gadermaier, G., et al. (2012). Distinct roles of secreted HtrA proteases from gram-negative pathogens in cleaving the junctional protein and tumor suppressor E-cadherin. J. Biol. Chem. 287, 10115-10120. doi: 10.1074/jbc.C111.333419

Humphreys, S., Stevenson, A., Bacon, A., Weinhardt, A. B., and Roberts, M. (1999). The alternative sigma factor, sigmaE, is critically important for the virulence of Salmonella typhimurium. Infect. Immun. 67, 1560-1568. doi: 10.1128/IAI.67.4.1560-1568.1999

Ikari, A., Ito, M., Okude, C., Sawada, H., Harada, H., Degawa, M., et al. (2008). Claudin-16 is directly phosphorylated by protein kinase A independently of a vasodilator-stimulated phosphoprotein-mediated pathway. J. Cell. Physiol. 214, 221-229. doi: 10.1002/jcp.21178

Ishizaki, T., Chiba, H., Kojima, T., Fujibe, M., Soma, T., Miyajima, H., et al. (2003). Cyclic AMP induces phosphorylation of claudin-5 immunoprecipitates and expression of claudin-5 gene in blood-brain-barrier endothelial cells via protein kinase A-dependent and -independent pathways. Exp. Cell Res. 290, 275-288. doi: 10.1016/s0014-4827(03)00354-9

Jeansonne, B., Lu, Q., Goodenough, D. A., and Chen, Y. H. (2003). Claudin-8 interacts with multi-PDZ domain protein 1 (MUPP1) and reduces paracellular conductance in epithelial cells. Cell. Mol. Biol. 49, 13-21.

Kaakoush, N. O., Castano-Rodriguez, N., Mitchell, H. M., and Man, S.II (2015). Global Epidemiology of Campylobacter Infection. Clin. Microbiol. Rev. 28, 687-720. doi: $10.1128 / \mathrm{cmr} .00006-15$

Kim, D. Y., and Kim, K. K. (2005). Structure and function of HtrA family proteins, the key players in protein quality control. J. Biochem. Mol. Biol. 38, 266-274. doi: $10.5483 /$ bmbrep.2005.38.3.266 
Kim, D. Y., Furuta, G. T., Nguyen, N., Inage, E., and Masterson, J. C. (2019). Epithelial Claudin Proteins and Their Role in Gastrointestinal Diseases. J. Pediatr. Gastroenterol. Nutr. 68, 611-614. doi: 10.1097/mpg.00000000 00002301

Konkel, M. E., Garvis, S. G., Tipton, S. L., Anderson, D. E., and Cieplak, W. (1997). Identification and molecular cloning of a gene encoding a fibronectin-binding protein (CadF) from Campylobacter jejuni. Mol. Microbiol. 24, 953-963. doi: 10.1046/j.1365-2958.1997.4031771.x

Krause, G., Winkler, L., Mueller, S. L., Haseloff, R. F., Piontek, J., and Blasig, I. E. (2008). Structure and function of claudins. Biochim. Biophys. Acta 1778, 631645. doi: 10.1016/j.bbamem.2007.10.018

Krause-Gruszczynska, M., Rohde, M., Hartig, R., Genth, H., Schmidt, G., Keo, T., et al. (2007a). Role of the small Rho GTPases Racl and Cdc42 in host cell invasion of Campylobacter jejuni. Cell. Microbiol. 9, 2431-2444. doi: 10.1111/ j.1462-5822.2007.00971.x

Krause-Gruszczynska, M., van Alphen, L. B., Oyarzabal, O. A., Alter, T., Hanel, I., Schliephake, A., et al. (2007b). Expression patterns and role of the CadF protein in Campylobacter jejuni and Campylobacter coli. FEMS Microbiol. Lett. 274, 916. doi: 10.1111/j.1574-6968.2007.00802.x

Krause-Gruszczynska, M., Boehm, M., Rohde, M., Tegtmeyer, N., Takahashi, S., Buday, L., et al. (2011). The signaling pathway of Campylobacter jejuniinduced Cdc42 activation: Role of fibronectin, integrin betal, tyrosine kinases and guanine exchange factor Vav2. Cell Commun. Signal. 9 (1), 32. doi: 10.1186/1478-811x-9-32

Lai, C. K., Chen, Y. A., Lin, C. J., Lin, H. J., Kao, M. C., Huang, M. Z., et al. (2016). Molecular Mechanisms and Potential Clinical Applications of Campylobacter jejuni Cytolethal Distending Toxin. Front. Cell. Infect. Microbiol. 6, 9. doi: $10.3389 /$ fcimb.2016.00009

Lal-Nag, M., Battis, M., Santin, A. D., and Morin, P. J. (2012). Claudin-6: a novel receptor for CPE-mediated cytotoxicity in ovarian cancer. Oncogenesis 1 (11), 33. doi: 10.1038 /oncsis. 2012.32

Lamb-Rosteski, J. M., Kalischuk, L. D., Inglis, G. D., and Buret, A. G. (2008). Epidermal growth factor inhibits Campylobacter jejuni-induced claudin-4 disruption, loss of epithelial barrier function, and Escherichia coli translocation. Infect. Immun. 76, 3390-3398. doi: 10.1128/iai.01698-07

Li, S. R., Dorrell, N., Everest, P. H., Dougan, G., and Wren, B. W. (1996). Construction and characterization of a Yersinia enterocolitica O:8 hightemperature requirement $(h t r A)$ isogenic mutant. Infect. Immun. 64, 20882094. doi: 10.1128/IAI.64.6.2088-2094.1996

Liao, Z. B., Yang, Z. G., Piontek, A., Eichner, M., Krause, G., Li, L. X., et al. (2016). Specific binding of a mutated fragment of Clostridium perfringens enterotoxin to endothelial claudin-5 and its modulation of cerebral vascular permeability. Neuroscience 327, 53-63. doi: 10.1016/j.neuroscience.2016. 04.013

Löwer, M., Weydig, C., Metzler, D., Reuter, A., Starzinski-Powitz, A., Wessler, S., et al. (2008). Prediction of extracellular proteases of the human pathogen Helicobacter pylori reveals proteolytic activity of the Hp1018/19 protein HtrA. PLoS ONE 3, 3510-3563. doi: 10.1371/journal.pone.0003510

Marder, E. P., Cieslak, P. R., Cronquist, A. B., Dunn, J., Lathrop, S., Rabatsky-Ehr, T., et al. (2017). Incidence and Trends of Infections with Pathogens Transmitted Commonly Through Food and the Effect of Increasing Use of CultureIndependent Diagnostic Tests on Surveillance - Foodborne Diseases Active Surveillance Network, 10 US Sites 2013-2016. MMWR Morb. Mortal Wkly. Rep. 66, 397-403. doi: 10.15585/mmwr.mm6615al

Mo, E., Peters, S. E., Willers, C., Maskell, D. J., and Charles, I. G. (2006). Single, double and triple mutants of Salmonella enterica serovar Typhimurium $\operatorname{deg} \mathrm{P}(h t r A), \operatorname{deg} \mathrm{Q}(h h o A)$ and $\operatorname{degS}(h h o B)$ have diverse phenotypes on exposure to elevated temperature and their growth in vivo is attenuated to different extents. Microb. Pathog. 41, 174-182. doi: 10.1016/j.micpath. 2006.07.004

Moese, S., Selbach, M., Zimny-Arndt, U., Jungblut, P. R., Meyer, T. F., and Backert, S. (2001). Identification of a tyrosine-phosphorylated $35 \mathrm{kDa}$ carboxy-terminal fragment (p35CagA) of the Helicobacter pylori CagA protein in phagocytic cells: processing or breakage? Proteomics 1, 618-629. doi: 10.1002/1615-9861(200104) 1:4<618::AID-PROT618>3.0.CO;2-C

Monkemuller, K., Wex, T., Kuester, D., Fry, L. C., Kandulski, A., Kropf, S., et al. (2012). Role of tight junction proteins in gastroesophageal reflux disease. $B M C$ Gastroenterol. 12:128. doi: 10.1186/1471-230x-12-128
Neddermann, M., and Backert, S. (2019). Quantification of serine protease HtrA molecules secreted by the foodborne pathogen Campylobacter jejuni. Gut Pathog. 11, 14. doi: 10.1186/s13099-019-0295-8

Nunbhakdi-Craig, V., Machleidt, T., Ogris, E., Bellotto, D., White, C. L., and Sontag, E. (2002). Protein phosphatase $2 \mathrm{~A}$ associates with and regulates atypical PKC and the epithelial tight junction complex. J. Cell Biol. 158, 967-978. doi: 10.1083/jcb.200206114

Piontek, J., Winkler, L., Wolburg, H., Muller, S. L., Zuleger, N., Piehl, C., et al. (2008). Formation of tight junction: determinants of homophilic interaction between classic claudins. FASEB J. 22, 146-158. doi: 10.1096/ fj. $07-8319$ com

Purdy, G. E., Hong, M., and Payne, S. M. (2002). Shigella flexneri DegP facilitates IcsA surface expression and is required for efficient intercellular spread. Infect. Immun. 70, 6355-6364. doi: 10.1128/iai.70.11.63556364.2002

Sayle, R. A., and Milnerwhite, E. J. (1995). RASMOL - biomolecular graphics for all. Trends Biochem. Sci. 20, 374-376. doi: 10.1016/s0968-0004(00) 89080-5

Schindelin, J., Arganda-Carreras, I., Frise, E., Kaynig, V., Longair, M., Pietzsch, T., et al. (2012). Fiji: an open-source platform for biological-image analysis. Nat. Methods 9, 676-682. doi: 10.1038/nmeth.2019

Schmidt, T. P., Perna, A. M., Fugmann, T., Bohm, M., Jan, H., Haller, S., et al. (2016). Identification of E-cadherin signature motifs functioning as cleavage sites for Helicobacter pylori HtrA. Sci. Rep. 6, 23264. doi: 10.1038/srep23264

Schmidt, A. M., Escher, U., Mousavi, S., Tegtmeyer, N., Boehm, M., Backert, S., et al. (2019). Immunopathological properties of the Campylobacter jejuni flagellins and the adhesin CadF as assessed in a clinical murine infection model. Gut Pathog. 11, 24. doi: 10.1186/s13099-019-0306-9

Schubert-Unkmeir, A., Konrad, C., Slanina, H., Czapek, F., Hebling, S., and Frosch, M. (2010). Neisseria meningitidis Induces Brain Microvascular Endothelial Cell Detachment from the Matrix and Cleavage of Occludin: A Role for MMP-8. PLoS Pathog. 6 (4), 1000874. doi: 10.1371/journal.ppat. 1000874

Shrestha, A., and McClane, B. A. (2013). Human Claudin-8 and-14 Are Receptors Capable of Conveying the Cytotoxic Effects of Clostridium perfringens Enterotoxin. mBio 4, e00594-e00512. doi: 10.1128/mBio.00594-12

Skorko-Glonek, J., Zurawa-Janicka, D., Koper, T., Jarzab, M., Figaj, D., Glaza, P., et al. (2013). HtrA Protease Family as Therapeutic Targets. Curr. Pharm. Des. 19, 977-1009. doi: 10.2174/1381612811319060003

Slifer, Z. M., and Blikslager, A. T. (2020). The Integral Role of Tight Junction Proteins in the Repair of Injured Intestinal Epithelium. Int. J. Mol. Sci. 21, 972. doi: $10.3390 / \mathrm{ijms} 21030972$

Szakal, D. N., Gyorffy, H., Arato, A., Cseh, A., Molnar, K., Papp, M., et al. (2010). Mucosal expression of claudins 2, 3 and 4 in proximal and distal part of duodenum in children with coeliac disease. Virchows Arch. 456, 245-250. doi: 10.1007/s00428-009-0879-7

Tegtmeyer, N., Wessler, S., Necchi, V., Rohde, M., Harrer, A., Rau, T. T., et al. (2017). Helicobacter pylori Employs a Unique Basolateral Type IV Secretion Mechanism for CagA Delivery. Cell Host Microbe 22, 552-560. doi: 10.1016/ j.chom.2017.09.005

Tegtmeyer, N., Sharafutdinov, I., Harrer, A., Esmaeili, D. S., Linz, B., and Backert, S. (2020). Campylobacter virulence factors and molecular host-pathogen interactions. Curr. Top. Microbiol. Immunol. (in press).

Tsukita, S., Tanaka, H., and Tamura, A. (2019). The Claudins: From Tight Junctions to Biological Systems. Trends Biochem. Sci. 44, 141-152. doi: 10.1016/j.tibs.2018.09.008

Turner, J. R. (2006). Molecular basis of epithelial barrier regulation - From basic mechanisms to clinical application. Am. J. Pathol. 169, 1901-1909. doi: 10.2353/ajpath.2006.060681

Van Itallie, C. M., and Anderson, J. M. (2014). Architecture of tight junctions and principles of molecular composition. Semin. Cell. Dev. Biol. 36, 157-165. doi: $10.1016 /$ j.semcdb.2014.08.011

Van Spreeuwel, J. P., Duursma, G. C., Meijer, C. J., Bax, R., Rosekrans, P. C., and Lindeman, J. (1985). Campylobacter colitis: histological immunohistochemical and ultrastructural findings. Gut 26, 945-951. doi: 10.1136/gut.26.9.945

Vecchio, A. J., and Stroud, R. M. (2019). Claudin-9 structures reveal mechanism for toxin-induced gut barrier breakdown. Proc. Natl. Acad. Sci. U. S. A. 116, 17817-17824. doi: 10.1073/pnas.1908929116 
Vogelmann, R., Amieva, M. R., Falkow, S., and Nelson, W. J. (2004). Breaking into the epithelial apical-junctional complex-news from pathogen hackers. Curr. Opin. Cell. Biol. 16, 86-93. doi: 10.1016/j.ceb.2003.12.002

Webb, B., and Sali, A. (2017). Protein Structure Modeling with MODELLER. Methods Mol. Biol. 1654, 39-54. doi: 10.1007/978-1-4939-7231-9_4

Wen, H. J., Watry, D. D., Marcondes, M. C. G., and Fox, H. S. (2004). Selective decrease in paracellular conductance of tight junctions: role of the first extracellular domain of claudin-5. Mol. Cell Biol. 24, 8408-8417. doi: $10.1128 / \mathrm{mcb} .24 .19 .8408-8417.2004$

Wilson, R. L., Brown, L. L., Kirkwood-Watts, D., Warren, T. K., Lund, S. A., King, D. S., et al. (2006). Listeria monocytogenes $10403 \mathrm{~S}$ HtrA is necessary for resistance to cellular stress and virulence. Infect. Immun. 74, 765-768. doi: 10.1128/iai.74.1.765-768.2006

Wooldridge, K. G., and Ketley, J. M. (1997). Campylobacter-host cell interactions. Trends Microbiol. 5, 96-102. doi: 10.1016/s0966-842x(97) 01004-4

Yamauchi, K., Rai, T., Kobayashi, K., Sohara, E., Suzuki, T., Itoh, T., et al. (2004). Disease-causing mutant WNK4 increases paracellular chloride permeability and phosphorylates claudins. Proc. Natl. Acad. Sci. U. S. A. 101, 4690-4694. doi: 10.1073/pnas.0306924101

Ye, M., Sharma, K., Thakur, M., Smith, A. A., Buyuktanir, O., Xiang, X., et al. (2016). HtrA, a Temperature- and Stationary Phase-Activated Protease Involved in Maturation of a Key Microbial Virulence Determinant, Facilitates Borrelia burgdorferi Infection in Mammalian Hosts. Infect. Immun. 84, 2372-2381. doi: 10.1128/iai.00360-16

Young, G. M., Schmiel, D. H., and Miller, V. L. (1999). A new pathway for the secretion of virulence factors by bacteria: The flagellar export apparatus functions as a protein-secretion system. Proc. Natl. Acad. Sci. U. S. A. 96, 6456-6461. doi: 10.1073/pnas.96.11.6456

Yuki, N., Susuki, K., Koga, M., Nishimoto, Y., Odaka, M., Hirata, K., et al. (2004). Carbohydrate mimicry between human ganglioside GM1 and Campylobacter jejuni lipooligosaccharide causes Guillain-Barre syndrome.
Proc. Natl. Acad. Sci. U. S. A. 101, 11404-11409. doi: 10.1073/pnas. 0402391101

Zarzecka, U., Modrak-Wojcik, A., Bayassi, M., Szewczyk, M., Gieldon, A., Lesner, A., et al. (2018). Biochemical properties of the HtrA homolog from bacterium Stenotrophomonas maltophilia. Int. J. Biol. Macromol. 109, 992-1005. doi: 10.1016/j.ijbiomac.2017.11.086

Zarzecka, U., Grinzato, A., Kandiah, E., Cysewski, D., Berto, P., Skorko-Glonek, J., et al. (2020). Functional analysis and cryo-electron microscopy of Campylobacter jejuni serine protease HtrA. Gut Microbes 12, 1-16. doi: 10.1080/19490976.2020.1810532

Zeissig, S., Burgel, N., Gunzel, D., Richter, J., Mankertz, J., Wahnschaffe, U., et al. (2007). Changes in expression and distribution of claudin 2, 5 and 8 lead to discontinuous tight junctions and barrier dysfunction in active Crohn's disease. Gut 56, 61-72. doi: 10.1136/gut.2006.094375

Zihni, C., Mills, C., Matter, K., and Balda, M. S. (2016). Tight junctions: from simple barriers to multifunctional molecular gates. Nat. Rev. Mol. Cell Biol. 17, 564-580. doi: 10.1038/nrm.2016.80

Zimmermann, L., Stephens, A., Nam, S. Z., Rau, D., Kubler, J., Lozajic, M., et al. (2018). A Completely Reimplemented MPI Bioinformatics Toolkit with a New HHpred Server at its Core. J. Mol. Biol. 430, 2237-2243. doi: 10.1016/j.jmb.2017.12.007

Conflict of Interest: The authors declare that the research was conducted in the absence of any commercial or financial relationships that could be construed as a potential conflict of interest.

Copyright (C) 2020 Sharafutdinov, Esmaeili, Harrer, Tegtmeyer, Sticht and Backert. This is an open-access article distributed under the terms of the Creative Commons Attribution License (CC BY). The use, distribution or reproduction in other forums is permitted, provided the original author(s) and the copyright owner(s) are credited and that the original publication in this journal is cited, in accordance with accepted academic practice. No use, distribution or reproduction is permitted which does not comply with these terms. 